\title{
La Iconografía Musical Como Materia Interdisciplinar Su Presencia En Los Estudios Musicales Universitarios En España
}

\author{
Carmen M. Zavala Arnal, Music Education PhD \\ University of Zaragoza, Spain
}

Doi:10.19044/esj.2020.v16n13p43～URL:http://dx.doi.org/10.19044/esj.2020.v16n13p43

\begin{abstract}
Resumen
En el presente artículo se pretende poner en relieve la naturaleza interdisciplinar de la iconografía musical como materia en relación a cuestiones epistemológicas y metodológicas. Para ello, además de establecer un estado de la cuestión, se acotan los términos "disciplina" e "interdisciplina", y en este último caso, se delimitan sus categorías. Además, se indaga acerca de la presencia de la iconografía musical como materia académica en los estudios de Grado de Musicología en España a través de sus planes de estudios. Se concluye que su presencia en el ámbito universitario es aceptable a tenor de los porcentajes obtenidos, si bien como materia optativa, y que conviene delimitar todavía ciertos preceptos en relación a la iconografía musical, especialmente de tipo metodológico.
\end{abstract}

Palabras Clave: Iconografía musical, Educación Musical, Musicología, Interdisciplinariedad 


\title{
Music Iconography as an Interdisciplinary Subject Its Presence in University Musical Studies in Spain
}

\author{
Carmen M. Zavala Arnal, Music Education PhD \\ University of Zaragoza, Spain
}

\begin{abstract}
This article aims to highlight the interdisciplinary nature of music iconography as a subject in relation to epistemological and methodological issues. In addition, to establishing the state of the question, the terms "discipline" and "interdisciplinary" are delimited, as well as their categories. Furthermore, it investigates about the presence of music iconography as an academic subject in Musicology Degree in Spain through its curriculum. It is concluded that its presence in the university field is acceptable, although as an optional subject, and that certain precepts should still be defined in relation to music iconography, especially in a methodological aspects.
\end{abstract}

Keywords: Music Iconography, Music education, Musicology, Interdisciplinarity

\section{Introducción y delimitación del concepto}

Podemos definir la iconografía musical como la disciplina que estudia las representaciones musicales en las artes visuales. Howard Mayer Brown (1980) ya la definió como una rama de la historia de la música que se interesa por el análisis e interpretación del contenido musical en las obras de arte, que puede revelar importante información acerca de la historia de los instrumentos, el estilo musical, la práctica interpretativa o la historia cultural o intelectual. Ya en 1970, Emanuel Winternitz, uno de los padres fundadores de la iconografía musical, puso en relieve su naturaleza interdisciplinaria, tanto en el ámbito académico como en el investigador, esperando además que esta ayudara "a liberar a la musicología del aislamiento en el que tantas ramas de investigación especializadas han caído por una especialización excesiva a veces" (Winternitz, 1972, pp. 80-90).

Desde aquí ya podemos atisbar la doble filiación de la iconografía musical, tal y como recogen definiciones ulteriores (Blazekovic, 2019). La propia interdisciplinariedad de la iconografía musical, por tano, hace compleja su delimitación y definición por su proximidad a la historia del arte y a la musicología. Hay quien opina que es una rama de la musicología, alegando 
que la investigación se dirige a aportar nuevos datos en el campo de la música aunque reconociendo la necesidad de utilizar métodos propios de la historia del arte, mientras que otros estudiosos consideran que "la consanguinidad de la iconografía musical con la historia del arte pesa más que cualquier parentesco" (Roubina, 2010, p. 1), y que la auténtica finalidad de la iconografía musical es el análisis de la obra artística, puesto que "lo que se analiza es obra de un artista plástico y no de un músico" (Álvarez, 1997, p. 774).

Por tanto, siendo también rama de la musicología, pues el núcleo de la investigación es la imagen musical, la metodología propia de la iconografía musical sigue los preceptos de la historia del arte, de manera que el primer paso para el estudio de una representación musical ha de ser la catalogación histórico-artística de la obra que la contiene. No obstante, en muchas ocasiones la validez de los estudios de iconografía musical no radica tanto en las conclusiones obtenidas relacionadas con la música como en el interés de la obra en sí misma y del proceso que explica la presencia de determinados elementos musicales. En cualquier caso, podríamos decir que la iconografía musical "está a medio camino entre la Musicología y la Historia del Arte, pues utiliza los conocimientos de la primera y los métodos de la segunda" (Álvarez, 1997, p. 782).

Con la metodología adecuada, a través de los estudios de iconografía musical se puede contribuir tanto a resolver cronologías y atribuciones problemáticas en una obra artística no documentada, como a identificar e interpretar una imagen musical que resulte compleja para un historiador del arte. Por un lado, esta dualidad epistemológica y metodológica puede ser entendida de forma errónea, según algunos investigadores, como "una especie de eclecticismo", sin embargo, es el resultado de su campo de investigación y especificidad (Baldassarre, 2000). Por otro lado, otras opiniones apuntan a que la iconografía musical necesitaría desarrollar una metodología propia para ganar autonomía como disciplina, especialmente en lo que se refiere a la utilidad de las imágenes musicales a través del análisis de sus evidencias musicológicas (Roubina, 2010, 2013).

Además, la iconografía musical y la organología, que se dedica al estudio de los instrumentos musicales y su clasificación, han estado tradicionalmente identificadas entre sí, aunque no son materias homologables (Álvarez, 1997). A partir de la segunda mitad del siglo XX comenzaron a desligarse y en la actualidad, sus cometidos están más delimitados. No obstante, la ausencia de una metodología específica exige cautela puesto que la línea divisoria entre la iconografía musical y la organología es a veces difusa. Para esta última, el objetivo final es el conocimiento anatómico del instrumento musical a través de la fuente artística para su posterior reconstrucción. Las reproducciones organológicas a partir de fuentes 
iconográficas tienen poco grado de autenticidad si no son contrastadas con otro tipo de fuentes históricas (Fernández de la Cuesta, 2013). Además, la iconografía musical y la organología actúan como interdisciplinas auxiliares, no sólo en la reconstrucción de instrumentos musicales, sino en los estudios de arqueología musical, que investiga los sonidos y las culturas musicales del pasado basándose fundamentalmente en fuentes organológicas e iconográficas, así como en los estudios sobre práctica interpretativa (Rault, 2004).

A continuación, abordamos los términos de "disciplina" e "interdisciplina", tratando de delimitar a cuál de las categorías de esta última correspondería la iconografía musical.

\section{La iconografía musical como interdisciplina}

Según el Seminario "La interdisciplinariedad en las universidades" celebrado en la Universidad de Niza de 1970, una disciplina es un "conjunto específico de conocimientos que tiene sus características propias en el terreno de la enseñanza, de la formación, de los mecanismos, métodos y materias" (Palmade, 1979, p. 21). Las disciplinas, por tanto, constituyen la base de la estructura académica y organizan el contenido científico (Morin, 2002), y su existencia en el ámbito educativo universitario ha sido observada tradicionalmente desde diferentes puntos de vista: como espacio intelectual, como territorio académico, como campo de enseñanza y como agrupamiento corporativo (Pedroza, 2006).

Ya en su momento, Boisot (1972, en Palmade, 1979) estableció que una disciplina comprende tres categorías:

-Son objetos observables/formalizados, y manipulados con la ayuda de métodos y procedimientos.

- Son fenómenos que no se materializan en la interacción entre estos objetos.

- Se rigen por leyes, cuya formulación depende de un conjunto de axiomas que permiten predecir su operación.

No obstante, el patrón disciplinario que se propone bajo estas premisas ha sido criticado por generar una división del conocimiento y por conformar entidades aisladas, con escasas relaciones entre ellas, que acaban siendo institucionalizadas, dando lugar a una organización académica universitaria fragmentada. La estructura académica de la universidad ha apostado tradicionalmente por la especialización disciplinar, creando una problemática de tipo conceptual y organizativa, aunque cabe señalar que esta especialización ha sido esencial para el progreso científico, al pretender superar el aislamiento que se produce entre las diversas disciplinas (Pedroza, 2006; Smirnov, 1983).

En este sentido, y atendiendo a este modelo individualizado, la iconografía musical todavía dista en la actualidad de alcanzar la categoría de 
disciplina, si bien es cierto que en el ámbito educativo universitario existe como materia académica tal y como veremos más adelante.

Por otro lado, la interdisciplinariedad se refiere a la interacción entre dos o más disciplinas, entre las que existen diferentes canales de comunicación. Esta interacción "puede ir de la simple comunicación de ideas hasta la integración mutua de conceptos directores, de la epistemología, de la terminología, de la metodología, de los procesos, de los datos y la organización de la investigación y de la enseñanza correspondiente (Apostel, Berger, Briggs y Michaud,1979; Piaget, 1979).

Si analizamos además otras acepciones clásicas del concepto, podemos delimitar con más concreción la categoría interdisciplinaria a la que puede pertenecer la iconografía musical. Atendiendo a la división de Heckhausen (Palmade, 1979, p. 23), esta podría considerarse una interdisciplina auxiliar, ya que se produce cuando una disciplina utiliza los métodos pertenecientes a otra: "el empleo de métodos que provienen de una disciplinariedad cruzada llegan a crear interdisciplinariedades auxiliares". En este sentido, la musicología utiliza métodos propios de la historia del arte. No obstante, dado que convergen metodologías de ambas materias, siguiendo con la categorización de Heckhausen, sería más correcto hablar de interdisciplinariedad compuesta, en tanto que las disciplinas están actuando para resolver un mismo problema, el análisis del contenido musical en una obra visual: "el vínculo que une disciplinas tan distintas reside en la imperiosa necesidad de encontrar soluciones técnicas que resistan las contingencias históricas, en constante evolución" (Palmade, 1979, p. 23).

Según Boisot (1972, en Palmade, 1979), se distinguen tres tipos de interdisciplinariedad, entre la que se encuentra la estructural, que es a la que debería aspirar la iconografía musical en tanto que existe una interacción entre dos o varias disciplinas, como son la musicología y la historia del arte, que debería conducir a la creación de un cuerpo de nuevas leyes, formando la estructura básica de una disciplina original que debería ser fruto de la reducida combinación formal de sus generadores. Como nueva disciplina, la iconografía musical podría seguir siendo la reunión de una parte de sus dos disciplinas de origen y de una zona disciplinar no incluida en la dos anteriores.

Por tanto, la naturaleza interdisciplinar de la iconografía musical, a cuyo enfoque no debe renunciar sino en todo caso ser complementado con otros, no es óbice para que esta desarrolle su propia identidad epistemológica y metodológica, traspasando las disciplinas académicas tradicionales de las que procede y creando un nuevo campo de conocimiento.

En relación al perfil académico y profesional del iconógrafo-musical, desde el enfoque interdisciplinar y desde el punto de vista metodológico, este debería tener conocimientos referidos a la historia del arte, pues el material primario con el que trabaja es la obra artística. Debe ser capaz de estudiar y 
catalogar las obras desde esta metodología, y conocer las tendencias artísticas de la época a la que estas pertenecen, así como el contexto social, cultural, filosófico y teológico en el que se crearon. Pero también debe ser un musicólogo, para identificar, describir, analizar y contextualizar las imágenes musicales (Álvarez, 1997).

Para ello, el nivel formativo del iconógrafo-musical debe integrar estudios musicales para poder identificar y comprender el contenido musical. Del mismo modo, debería tener formación en disciplinas humanísticas de contenidos históricos y filosóficos (Gómez, 2006). Si, además, se aplica la iconografía musical al campo de la docencia, deberá tener una capacitación pedagógica derivada de estudios relacionados con los procesos de enseñanzaaprendizaje y la didáctica. No obstante, para utilizar de manera puntual las imágenes musicales como herramienta didáctica en la enseñanza musical, no es necesario ser un iconógrafo-musical, sino acudir a estudios especializados sobre la materia y atender a una serie de referencias y reflexiones sobre el valor y uso de los mismos.

\section{La iconografía musical en los planes de estudios musicales universitarios en España}

En España, la iconografía musical ha experimentado un importante auge en las dos últimas décadas, motivado por el apoyo institucional recibido para tal fin. La iconografía musical ha pasado de ser un campo parcial de la musicología a convertirse en una asignatura presente en los planes de estudios de algunas universidades españolas.

Desde la Sociedad Española de Musicología (SEdeM) se ha fomentado la presencia de esta materia desde que en el año 1997 se le dedicara una sesión científica en su IV Congreso, al que siguieron otros en los que la iconografía musical ha estado siempre presente a través de comunicaciones científicas, clara muestra del creciente interés que despierta esta disciplina (Piquer, 2013).

El ámbito institucional y universitario ha propiciado en los últimos años el encuentro entre investigadores de iconografía musical, lo que ha favorecido la creación de nuevas asociaciones y grupos de investigación. En el año 2002 nacía el Grupo de Investigación sobre Iconografía Musical de la Universidad Complutense de Madrid, entre cuyas principales actividades se encuentra la realización de la catalogación de los fondos del Museo Nacional del Prado, bajo el nombre "El sonido de la pintura en el Museo del Prado" (Bethencourt, Carvajal y Palacios, 2012).

Vinculada a este grupo de investigación, se encuentra la Asociación Española de Documentación Musical (AEDOM), dependiente de la Asociación Internacional de Bibliotecas Musicales (AIBM/IAML), que creó en 2007 una sección dedicada a la iconografía musical, con el fin de realizar trabajos de catalogación y difusión de sus fuentes, y establecer una red de 
intercambio abierta entre investigadores (Cano, Rocha, Correia, Luengo y Rubiales, 2012).

En relación al lugar académico que ocupa la iconografía musical en los estudios universitarios en España, debemos antes señalar que la universidad sigue las consignas exigidas por el proceso de construcción del Espacio Europeo de Educación Superior, iniciado en 1999 con la Declaración de Bolonia, con varias leyes estatales en vigor. En concreto, a través del Real Decreto 1393/2007, de 29 de octubre, modificado por el Real Decreto 861/2010, de 2 de julio, se ordenaron las materias básicas por rama de conocimiento: Artes y Humanidades, Ciencias Sociales y Jurídicas, Ciencias, Ciencias de la Salud, Arquitectura e Ingeniería, y se agrupan las competencias que los estudiantes deben adquirir durante sus estudios. Además, en el Real Decreto 22/2015, de 23 de enero y en el Real Decreto 1027/2011, de 15 de julio, en el que establece el Marco Español de Cualificaciones para la Educación Superior, que son la siguientes: Nivel 1- Técnico Superior, Nivel 2 - Grado-, Nivel 3 - Máster-, y nivel 4 -Doctor.

En la actualidad, la musicología en la Universidad española es materia de diversas asignaturas correspondientes a las titulaciones del Grado en Musicología (recibe el mismo nombre que la especialidad del Grado en Música impartido en los conservatorios superiores), y Grado en Historia y Ciencias de la Música (con objetivos, competencias y estructura similares al anterior) (Casares, 1986; López-Calo, 2014; Martín, 2005).

Durante el curso 2019/2020, estas titulaciones se imparten en las siguientes universidades españolas:

- Grado en Musicología: Universidad Autónoma de Barcelona, Universidad Complutense de Madrid, Universidad Alfonso X el Sabio, en Madrid, Universidad Católica de Murcia, y Universidad Internacional de Valencia.

- Grado en Historia y Ciencias de la Música: Universidad de Granada, Universidad de Oviedo, Universidad de Salamanca, Universidad de Valladolid, y Universidad Autónoma de Madrid.

En el ámbito universitario español, la musicología como materia también se incorpora a otros estudios de Grado relacionados con las ramas de conocimiento de las Artes y Humanidades. Es el caso de la integración en los planes de estudio del Grado en Historia del Arte que imparten algunas universidades de asignaturas de carácter obligatorio y/o optativo relacionadas con la Historia de la Música. También en la rama de las Ciencias Sociales y Jurídicas, a través de algunos contenidos específicos de la asignatura "Fundamentos de Educación Musical" que forma parte del currículo en el Grado en Magisterio en Educación Primaria en muchas universidades españolas.

En relación a la iconografía musical en las enseñanzas universitarias, en las dos últimas décadas, esta ha experimentado en España un importante 
impulso en el ámbito educativo (Zavala, 2018). Además de haber sido objeto de varios grupos de investigación universitarios, de los que hemos hablado anteriormente, la iconografía musical se ha convertido en una asignatura presente en algunos planes de estudios universitarios. A continuación, citamos algunos de los estudios de Grado y Máster en los que se ha impartido la iconografía musical como asignatura durante el curso 2019/20 en universidades españolas, a través de la revisión de sus currículos.

- Estudios de Grado:

- Grado en Musicología de la Universidad Complutense de Madrid, asignatura optativa "Iconografía Musical" (6 créditos), curso $3^{\circ}$, módulo: Fundamentos de musicología, materias: "Teoría y técnicas auxiliares de la musicología".

- Grado en Musicología de la Universidad Autónoma de Barcelona, asignatura optativa "Iconografía Musical" ( 6 créditos), curso $3^{\circ}$ o $4^{\circ}$.

- Grado en Historia y Ciencias de la Música de la Universidad de Oviedo, asignatura optativa "Iconografía Musical" (6 créditos), curso $3^{\circ}$, materia: "Patrimonio Musical".

- Grado en Historia y Ciencias de la Música de la Universidad de Salamanca, asignatura optativa "Iconografía Musical" (6 créditos), curso $4^{\circ}$.

- Grado en Historia y Ciencias de la Música Universidad de Valladolid, asignatura optativa "Organología e Iconografía Musical" (6 créditos), curso $3^{\circ}$.

- Grado en Musicología de la Universidad Internacional de Valencia (VIU), asignatura optativa "Iconografía Musical" (6 créditos), $4^{\circ}$ curso, mención I: "Patrimonio musical español e iberoamericano".

- Grado en Musicología de la Universidad Alfonso X el Sabio, asignatura optativa "Iconografía Musical" (6 créditos), $3^{\circ}$ curso.

- Estudios de Máster:

- Máster Oficial en Patrimonio Musical Universidad de Granada, Universidad Internacional de Andalucía y Universidad de Oviedo, asignatura obligatoria "Difusión del patrimonio musical: iconología, organología y exposiciones" (5 créditos).

- Máster en Música Española e Hispanoamericana de la Universidad Complutense de Madrid, asignatura "Metodología de la investigación musicológica. Patrimonio, documentación e iconografía musical" (6 créditos).

Según este análisis, obtenemos como resultado a través de una medición cuantitativa (Bisquerra, 2000), que de los diez Grados en Musicología e Historia y Ciencias de la Música que se imparten ahora mismo en España, siete incluyen en su currículo una asignatura relacionada con la iconografía musical, si bien en el $100 \%$ de los casos se trata de una asignatura optativa. Además, esta comienza a estar presente en algunos estudios especializados de Máster. 


\section{Conclusiones}

Tal y como han establecido varios estudiosos de la iconografía musical (Álvarez, 1997; Baldassarre, 2000; Blazekovic, 2019; Roubina, 2010, 2013), se trata de una materia de tipo interdisciplinar en la que convergen aspectos metodológicos de la historia del arte, pero cuyo análisis e interpretación de sus contenidos musicales ha de abordarse desde la musicología. También se ha demostrado en el presente artículo esta naturaleza interdisciplinar a través de la delimitación de los conceptos de disciplina e interdisciplina y sus distintas categorías.

Se debe, por tanto, aceptar esta naturaleza interdisciplinar, no como dicotomía sino como virtud, si bien se hace necesario todavía delimitar ciertos preceptos, especialmente metodológicos.

Tal y como se ha mostrado, la iconografía musical está presente en los estudios universitarios en España en los Grados en Musicología e Historia y Ciencias de la Música no así en los estudios de Grado en Historia del Arte, pues aunque precisa de la metodología propia de esta materia, el centro de estudio es de tipo musical. No obstante, se ha señalado la necesidad de que los estudiosos de iconografía musical posean una sólida formación históricoartística.

Todo lo expuesto nos lleva a referir la peculiaridad de la iconografía como materia interdisciplinar, así como la importancia a tenor de los resultados, que esta ha ido adquiriendo en el ámbito de los estudios musicales universitarios. Sería deseable en el futuro una mayor presencia en este ámbito, que ha de ser fruto del desarrollo de sus metodologías.

\section{References:}

1. Álvarez, R. (1997). Iconografía musical y organología. Revista de Musicología, 20 (2), pp. 767-782.

2. Apostel L., Berger, G., Briggs, A. y Michaud, G. (1979). Interdisciplinariedad. Problemas de la enseñanza y de la investigación en las universidades. México: ANUIES.

3. Baldassare, A. (2000). Reflections on Methods and Methodology in Music Iconography. Music in Art. International Journal for Music Iconography, Research Center for Music Iconography, 25 (1-2), pp. 33-38.

4. Baldassare, A. (2000). Music Iconography: What is it all about? Some remarks and considerations with a selected Bibliography. Ictus, 9 (2), pp. 69-114.

5. Bethencourt, F., Carvajal, A. y Palacios, M. (2012). Aspectos científicos y modelos de investigación en España. En C. Bordas e I. Rodríguez (eds.), El proyecto UCM. Imagen es Música. Recursos para 
la catalogación y estudio de fuentes de Iconografía Musical en España y Portugal (pp. 22-45). Pozuelo de Alarcón (Madrid): AEDOM.

6. Bisquerra, R. (2000). Métodos de investigación educativa: guía práctica. Barcelona: CEAC.

7. Blazekovic, Z. (2019). Music and Iconography. En J. Sturman (ed.), The SAGE International Encyclopedia of Music and Culture (pp. 1-5). Arizona, Sage Publishing.

8. Brown, H. M. (1980). Iconography of music. En S. Sadie (ed.), The New Grove Dictionary of Music and Musicians, 9, (pp. 11-189). Londres: Macmillan.

9. Cano, J. I., Rocha, L., Correia, L., Luengo, P. y Rubiales, G., (2012). Las propuestas hispanoportuguesas: SEMA, UCM/Prado, UNL, IAPH, AEDOM. En C. Bordas e I. Rodríguez (eds.), El proyecto UCM. Imagen es Música. Recursos para la catalogación y estudio de fuentes de Iconografía Musical en España y Portugal (pp. 86-108). Pozuelo de Alarcón (Madrid), AEDOM.

10. Casares, E. (1986). Presente y futuro de la música en la Universidad Española. I Simposio Nacional de didáctica de la música. Madrid: Escuela Universitaria de Formación del Profesorado María Díaz Jiménez de Madrid, pp. 153-160.

11. Cobo, J. M. (1986). Interdisciplinariedad y Universidad. Madrid: Universidad Pontificia de Comillas.

12. Fernández de la Cuesta, I. (2013). De la Historia del Arte a la Musicología. Sobre la iconografía musical en las representaciones artísticas medievales" Alma ars: estudios de arte e historia en homenaje al Dr. Salvador Andrés Ordax, pp. 190-191.

13. Gómez Muntané, $M^{a}$ C. (2006). Algunas reflexiones sobre el caso de la Musicología. Nassarre: Revista Aragonesa de Musicología, 22 (1), pp. 739-740.

14. Herrán, A. (2011). Complejidad y Transdisciplinariedad. Revista Educação Skepsis, 2, (I). São Paulo (Brasil), 294-320.

15. López-Calo, J. L. (1986). La música en la Universidad en España y en Europa: notas históricas. I Simposio Nacional de didáctica de la música. Madrid. Madrid: Escuela Universitaria de Formación del Profesorado María Díaz Jiménez de Madrid. pp. 161-210.

16. López-Calo, J. L. (2014). La entrada de la musicología en la universidad Española. Notas históricas y recuerdos personales. Allegro cum laude: estudios musicológicos en homenaje a Emilio Casares, 3948.

17. Martín, A. (2005). El Grado en Musicología y el Grado en Historia y Ciencias de la Música: Pasado, Presente y Futuro de la Musicología en 
la Universidad española. Revista interuniversitaria de formación del profesorado, 52, 53-76.

18. Morin, E. (1995). Sobre la interdisciplinaridad. Zaragoza: Universidad de Zaragoza.

19. Morin, E. (2001). La cabeza bien puesta. Repensar la reforma, reformar el pensamiento. Buenos Aires: Nueva Visión.

20. Palmade, G. (1979). Interdisciplinariedad e ideologías. Madrid: Narcea.

21. Pedroza, R. (2006). La interdisciplinariedad en la Universidad. Tiempo de educar, 7 (13), 69-98.

22. Piquer Sanclemente, R., (2013). Aquello que se escucha con el ojo: la iconografía musical en la encrucijada. Síneris. Revista de Musicología, 9, 1-17.

23. Rault, CH. (2004). Aspectos de la relación entre la iconografía medieval y la práctica interpretativa. Revista Catalana de Musicologia, 2, 11-19.

24. Real Decreto 1393/2007, de 29 de octubre, modificado por el Real Decreto 861/2010, de 2 de julio, en BOE n ${ }^{\circ} 260$, de 30 de octubre de 2017:

https://www.boe.es/buscar/act.php?id=BOE-A-2007-18770

25. Real Decreto 1027/2011, de 15 de julio, en BOE $n^{\circ} 185$, de 3 de agosto de 2011:

https://www.boe.es/buscar/doc.php?id=BOE-A-2011-13317

26. Roubina, E. (2010). ¿Ver para creer?: una aproximación metodológica al estudio de la iconografía musical novohispana. Anais do SIMPOM, $1,1-21$.

27. Roubina, E. (2013). ¿Una imagen vale más...?: pautas para el estudio de las evidencias organológicas en la iconografía musical novohispana. Cátedra de Artes, 13, 40-69.

28. Smirnov, S. N. (1983). La aproximación interdisciplinaria en la ciencia de hoy. Fundamentos ontológicos y epistemológicos formas y funciones. En T. Bottomore (coord.), Interdisciplinariedad y ciencias humanas (pp. 71-164). Madrid: Tecnos-Unesco.

29. Winternitz, E. (1972). The Iconology of Music: Potential and Pitfalls. En B. S. Brook et al. (ed.), Perspectives in Musicology (pp. 80-90). Nueva York: Norton.

30. Zavala Arnal, C. M. (2018). La imagen artística en la educación musical: una reflexión acerca de su uso. Revista Internacional de Educación Musical, 6, 37-41. 